UDC 330(075.8)

LBC 65.012

\title{
THE POLARIZATION OF THE CORPORATE CAPITAL IN THE CONDITIONS OF PROFOUND TECHNOLOGICAL CHANGES
}

\author{
Olga V. Brizhak \\ Kuban State Technological University, Krasnodar, Russian Federation
}

Marina E. Buyanova

Volgograd State University, Volgograd, Russian Federation

\begin{abstract}
Technological changes in the modern economy are due to qualitative modifications in the material and technical basis of production with the help of computer technology and the Internet system, which is a global information resource and a reflected form of universal productive forces created and used collectively. Information technologies used in the process of enterprise management allow transforming the organizational structure of economic relations into a network form. The article reveals the essence of corporate capital polarization in the conditions of deep technological shifts. The attention is paid to the corporate and network forms of economic relations. The authors reveal the virtual component of increasing polarization of corporate capital and its fictitious form. The specificity of its virtual form acquires a new qualitative basis in network-type corporations, forming the conditions for accelerated fictitious transactions with the help of Internet technologies. As a result of the global generalization and informatization of capital, corporate and network forms are merging, forming a total market of corporate networks. The article shows that in the corporate sector of the Russian economy, such interaction is weakened, and the scale of the network form is insufficient, therefore, the movement of this contradiction is not on the path of synthesis, but on the path of polarization. The economic system of Russia demonstrates the stagnation of changes of the corporate capital and its integration in the economic system.

The authors propose to use the following measures for ensuring an additional source of developing resources in the conditions of low investment attractiveness: the reproduction of fictitious capital, the restoration of public confidence in national financial markets, carrying out protectionist policies, import substitution and reindustrialization.

Key words: corporate capital, corporate structure, network form of organization, economic relations, polarization, stagnated development, raw materials economy, reindustrialization, protectionism.
\end{abstract}

УДК $330(075.8)$

ББК 65.012

\section{ПОЛЯРИЗАЦИЯ КОРПОРАТИВНОГО КАПИТАЛА В УСЛОВИЯХ ГЛУБОКИХ ТЕХНОЛОГИЧЕСКИХ ПРЕОБРАЗОВАНИЙ}

\section{Ольга Валентиновна Брижак}

Кубанский государственный технологический университет, г. Краснодар, Российская Федерация

\section{Марина Эдуардовна Буянова}

Волгоградский государственный университет, г. Волгоград, Российская Федерация

Аннотация. Технологические преобразования современной системы экономики обусловлены каче-
ственными преобразованиями материально-технической основы производства с помощью компьютерной
техники и системы Интернет, которая является глобальным информационным ресурсом и отраженной фор-
мой всеобщих производительных сил, создаваемых и используемых коллективно. Информационные техно-
логии, применяемые в процессе управления предприятием, позволяют преобразовать организационную
структуру экономических отношений в сетевую форму. В статье раскрывается сущность поляризации кор- 
поративного капитала в условиях глубоких технологических сдвигов. Обращается внимание на корпоративную и сетевую формы организации экономических отношений. Авторами раскрывается виртуальный компонент усиливающейся поляризации корпоративного капитала и его фиктивной формы. Специфика его виртуальной формы приобретает в корпорациях сетевого типа новое качественное основание, формируя условия для ускорения фиктивных трансакций с помощью интернет-технологий. В результате глобального обобществления и информатизации капитала происходит сращивание корпоративной и сетевой форм, при котором образуется тотальный рынок корпоративных сетей. В статье показано, что в корпоративном секторе российской экономики такое взаимодействие ослаблено, а масштабность сетевой формы недостаточна, следовательно, движение указанного противоречия осуществляется не по пути синтеза, а по пути поляризации. В экономической системе России реализуется сценарий заторможенного преобразования корпоративного капитала и способа его встраивания в систему экономики.

Авторами в качестве источника дополнительных ресурсов развития в условиях низкой инвестиционной привлекательности предложено использование возможностей воспроизводства фиктивного капитала, восстановление общественного доверия к национальному финансовому рынку, проведение протекционистской политики, импортозамещения и реиндустриализации.

Ключевые слова: корпоративный капитал, корпоративная структура, сетевая форма организации, экономические отношения, поляризация, заторможенное развитие, сырьевая экономика, реиндустриализация, протекционизм.

Процессы масштабных технологических преобразований, совершаемые как на мировом, так и на национальном уровне, демонстрируют утверждение шестого уклада, инициируя соответствующие инновации в области организации хозяйственных отношений, институциональной среде, в новых формах социально-экономического развития [5]. Последствия воздействия научно-технологических трансформационных процессов на движение корпоративного капитала формируют основу для ускорения глобальных постиндустриальных преобразований и перехода к новой экономической реальности, отличной от условий функционирования индустриальной экономики. Формирующаяся система глобальной экономики и ее компоненты в динамично возрастающем потоке преобразований распадаются на части целостной системы, нарушаются связи, в них нарастает несогласованность и несоответствие, что подрывает системное качество входящих в эти связи элементов и актуализирует задачу восстановления указанных системных связей. Научно-техническая революция обусловила качественное преобразование производительных сил и кардинально изменила материально-техническую основу производства с помощью компьютерной техники и мировой системы Интернет, которая является глобальным информационным ресурсом и отраженной формой всеобщих производительных сил, создаваемых и используемых только коллективно.
Так, доля «информационной индустрии в России на современном этапе составляет 3,3 \% ВВП. В большинстве развитых стран этот показатель находится на уровне $5 \%$, в Великобритании, Ирландии, Кореи, США, Японии составляет 7 \%. Доля IT-индустрии в ВВП России на период 2016 года составила 2,9\%. Объем валовой добавленной стоимости в реальном выражении достиг 2265 млрд руб., прирост по сравнению с 2010 г. в постоянных ценах - $19 \%$ (в 2,7 раз выше, чем прирост ВВП), по сравнению с 2015 г. - снижение на $5 \%$. Среди зарубежных стран наиболее высока доля информационного сектора в ВВП в Республике Корея (11\%), Японии, Швеции, США - 6-7\%, сопоставимая с Россией $(3,3-$ 3,5 \%) - в Польше, Норвегии, Греции» [11].

Обратим внимание на организационные параметры современных технологических преобразований, так как в них происходит раздвоение экономических форм организации на корпоративный и сетевой. Корпоративная форма организации экономических отношений основана на институционализации поведения агентов с присущими им внутренними противоречиями. Сетевая форма организации экономических отношений в отличие от корпоративной является результатом социализации хозяйственной деятельности, в результате которой происходит всестороннее преобразование технологического базиса производства на основе внедрения компьютерных технологий. 


\section{ЭКОНОМИЧЕСКАЯ ТЕОРИЯ}

Виртуализация, затрагивая экономические отношения в сфере производства, приводит к усиливающейся поляризации корпоративного капитала и его фиктивной формы. Специфика его виртуальной формы приобретает в корпорациях сетевого типа новое качественное основание, формируя условия для ускорения фиктивных трансакций с помощью интернет-технологий. В сетях переливаются потоки информации, реализуются экономические интересы, формируется новое знание. Постиндустриальные корпорации существенно меняют свои очертания и напоминают высокотехнологичную креативную рассеянную мануфактуру. Каждый из работников в этой огромной сети может находиться удаленно, будучи связан через Интернет с единой корпоративной структурой, и осуществлять разработки, не требующие специального оборудования или сложной системы финансовых операций. Этот новый тип сетевой кооперации рождает новый феномен - феномен «сетевой фирмы» (М. Кастельс) [9], то есть структуры, при которой каждый раз под новый крупный заказ фирма по-новому строит конфигурацию производства, иногда выходя за рамки одной корпорации, а прежний тип управления и власти - технократию - сменяет «меритократия» (Д. Белл) [1]. М. Кастельс, изучая экономику сетевых структур, утверждает, что «жизнь глобального капитала все меньше и меньше зависит от конкретного труда и все больше и больше от накопленного объема труда как такового, которым управляет небольшой мозговой центр, обитающий в виртуальных дворцах глобальных сетей» [9].

Если у Маркса в «Капитале» существует постановка проблемы технологической границы корпоративного капитала, основанной на кооперации, внутрифирменном разделении труда и взаимодействии различных фирм [12], то с появлением информационных технологий и сетевых систем эта граница начинает размываться. Сетевая корпорация показывает проблему размывания границы корпорации и диффузии макро- и микроуровней, что становится реалией для новой экономики. В информационном обществе «все зависит от быстроты ответа на запросы глобального рынка и адаптивности, значит сети в нем важнее всего» [9]. Такая гибкая модель сетевой организации является процессом, обусловленным, с одной стороны, новыми технологическими задачами, а с другой - новыми формами поиска эффективного использования человеческого потенциала работников.

Вместе с тем обобществление производительных сил и развитие всеобщего творческого труда не гарантирует общественный контроль над современными высокими технологиями и технологиями создания и функционирования сетей и равный доступ к ним. Как правило, обладателями прогрессивных знаний и инноваций являются страны с развитой рыночной экономикой, оказывающие воздействие на уровень доходности и отдачи от инвестиций, а также контроль над воспроизводством знаний.

Сетевизация экономических отношений воспроизводит особые виртуальные формы данных отношений, погружая в виртуальную реальность хозяйственную действительность. С одной стороны, виртуализация ослабляет причинно-следственные связи в реальном секторе экономики и формирует разрыв между ним и финансовым рынком. Виртуализация становится своего рода замещением реальности ее симуляцией, то есть образом реальности. С другой стороны, она отражает объективные процессы эволюционного движения, то есть переход из одной формы в другую с наибольшим потенциалом, принимая мнимое качество образа базовой формы действительно существующей. «Виртуальная реальность превращает традиционные организации в корпоративные бизнес-системы с элементами потоков работ. Сформировавшееся виртуальное коммуникационное пространство делает неактуальными требования традиционных организаций (табельный учет, своевременный приход на работу), меняет ее структурные аспекты, позволяя заказчику принимать непосредственное участие в работе организации в сетевой доступности» [10].

В таблице проанализированы условия взаимодействия и развития корпоративной и сетевой форм организации экономических отношений в среде новой экономики - экономике знаний и информации.

В дополнение к приведенной таблице надо сказать, что сетевая форма организации экономики не отрывается от реального производства, а органично интегрирована в него во 
всем богатстве креативных продуктов и знаний, востребованных материальным производством и инвестиционным спросом [9]. Особое значение в инвестиционном процессе имеет фиктивный капитал, связывающий между собой корпоративную и сетевую экономику.

Продолжим политико-экономическое исследование указанных форм экономических отношений, взяв за основу работы А.В. Бузгалина и А.И. Колганова. Авторы определяют корпоративный капитал как территорию репродуктивного труда, а сетевые связи - как территорию творческой деятельности [5, c. 141-153], продолжая идеи К. Маркса о труде в обществе [13] и теорию креативного класса Р. Флориды [17]. «Реальностью современных тенденций противоречивого развития глобального обобществления и информационных технологий является сращивание корпоративной и сетевой форм, образующее корпоративные сети, контролирующие рынок или рынок тотальной власти корпоративных сетей, где место отдельных обособленных единиц занимают аморфные, врастающие друг в друга сети, причем действующие в большинстве случаев либо вне материального производства, либо в "превратном (бесполезном) секторе" экономики (финансовый, бюрократический, военно-промышленный и т. д.)» [4, с. 149]. Современные постиндустриальные трансформации формируют зоны инновационных центров и периферии в глобальной экономике, где по-разному, на различных скоростях и полюсах осуществляются научно-технологические преобразования, поляризуя указанные формы организации корпоративного капитала [15; 16].
В результате поляризации экономических отношений в странах центра технологических преобразований происходит формирование сетевой надстройки над корпоративным капиталом, при этом усиливается манипулятивный контроль корпоративного капитала.

В странах, находящихся на периферии технологического прогресса, срабатывает эффект сдерживания процесса соединения корпоративной и сетевой форм организации экономических отношений ввиду их заторможенного формирования и распространения [5]. Стратегическая линия развития российской экономики ориентирована на рентный компонент от производства и продажи сырьевых ресурсов, что ослабляет соединение корпоративных и сетевых форм организации экономических отношений и усиливает технологическую зависимость. Ключевой проблемой является спрос на инновации, а также его неэффективная структура - избыточный перекос в сторону закупки готового оборудования за рубежом в ущерб внедрению собственных разработок и имитация российской инновационной системы, ориентированной на заимствование готовых технологий, а не на создание собственных прорывных инноваций. Среди стран ОЭСР Россия занимает последнее место по доле передовых компаний новаторов. Таких среди российских инновационно активных предприятий насчитывается всего $16 \%$ по сравнению, например, с 55 \% в Дании и Финляндии [8].

Сказанное выше свидетельствует о наличии системного барьера на пути увеличения сетевых структур в отечественной экономике из-за низкого спроса на инновации. Про-

\section{Корпоративная и сетевая формы организации экономических отношений} в условиях новой экономики

\begin{tabular}{|l|c|c|}
\hline \multicolumn{1}{|c|}{ Критерии типизации } & \multicolumn{2}{|c|}{ Формы организации отношений } \\
\cline { 2 - 3 } & Корпоративная & Сетевая \\
\hline Базовое условие & Капитализация & Наполнение знаниями \\
\hline Сфера доминирования & $\begin{array}{c}\text { Индустриальное } \\
\text { производство }\end{array}$ & Сфера услуг \\
\hline Разновидность производства & Массовое & Индивидуальное \\
\hline $\begin{array}{l}\text { Производственная функция: преоб- } \\
\text { ладающие факторы }\end{array}$ & $\begin{array}{l}\text { Технология, } \\
\text { организация }\end{array}$ & Информация, знания \\
\hline $\begin{array}{l}\text { Связь между производством и по- } \\
\text { треблением }\end{array}$ & Косвенная & Прямая интерактивная \\
\hline Продвижение продуктов на рынок & Маркетинг-индустрия & Сетевой маркетинг \\
\hline
\end{tabular}

Примечание. Составлено авторами. 
тиворечия развития постиндустриальных тенденций и изменения в технологиях материального производства, их геоэкономическом распределении утвердили важность проведения политики реиндустриализации - развития нового качества материального производства, снимающего ограничения как классического индустриализма, так и господствовавших в последние десятилетия неолиберальных форм постиндустриальных тенденций. Для российской экономики, где корпорации играют определяющую роль в стратегически важных отраслях и где до сих пор относительно низок уровень инновационной активности и социальной ответственности этой подсистемы национальной экономики, реиндустриализация стала жизненно необходимой [7].

Результаты анализа выборки крупных корпораций отечественной экономики показывают неустойчивое возвышение сетей над базисом большинства сырьевых корпораций и деградацию индустриального комплекса корпоративной формы организации экономических отношений. Данные эмпирического анализа показателей индустриального спада показывают ситуацию в станкостроении. Уровень производства станков в России упал до 3,2 тыс. штук в 2012 г. по сравнению с 129,8 тыс. штук в 1990 году. В 2012 г. Россия продала 307 промышленных роботов, а Германия 14 500, количество эксплуатируемых на 10 тыс. занятых в промышленности в Южной Корее составило 396 единиц, в Японии - 332, в Германии - 273, а в России - всего два. Пришли в упадок многие высокотехнологичные отрасли. Так, при сравнительно небольшом (на 18,1 \%) спаде в производстве стали производство высокотехнологичных видов проката и других конструкционных материалов из стали сократилось в 3-8 раз [2].

Индустриальная деградация - один из главных результатов поляризации корпоративного капитала в странах, находящихся на периферии социально-экономических преобразований. Необходимо активизировать взаимодействие и синтез корпоративной и сетевой форм организации экономических отношений и повысить значимость сетевой формы организации.

Так как в корпоративном секторе российской экономики такое взаимодействие ослаб- лено, а масштабность сетевой формы недостаточна, то и движение указанного противоречия осуществляется не по пути синтеза, а по пути поляризации. В экономической системе России реализуется сценарий заторможенного преобразования корпоративного капитала и способа его встраивания в систему экономики.

Если немногие российские высокотехнологичные сетевые структуры стремятся основательно встроиться в центральную (ядерную) зону глобальной экономики и извлечь из этого дополнительные преимущества, то сырьевые корпорации ограничиваются встраиванием в периферийную зону глобальной экономики.

Проведенное исследование крупнейших компаний - лидеров в отраслях промышленности показало размеры вложения в инновационное развитие корпораций: «Алроса» 2,7 млрд руб., «Евраз»-1,5 млрд руб., «РЖД»1,1 млрд руб., «Энергия» - 103,8 млн рублей. По отношению к выручке от продаж соответствующих компаний это очень низкий уровень инвестиций $-1,3 \%, 0,3 \%, 0,1 \%, 0,3 \%$ соответственно [3].

При сравнении с величиной средств, вкладываемых в инновации, российские компании значительно отстают от крупнейших зарубежных компаний. Например, удельный вес компаний, осуществляющих технологические инновации за период с 2008 г. по 2012 г. на уровне высокого удельного веса компаний Бразилии 62,5 \%, Бельгии 51,4 \%, завершая Венгрией - 20,1 \% и Латвией - 16,2 \% и России $-8,0 \%$, в 2008 г. для России изменился ненамного - в 2012 г. составил 9,1\%. Тогда как наибольший удельный вес определился для ЮАР - 65,4 \%, Германии - 64,2 \%, Румынии $14,3 \%$, Мексики - 10,2 \% [9].

Вышеизложенное в части инновационных вложений крупнейших российских корпораций промышленности характеризует серьезную проблему в перспективах их прогрессивного развития.

Соответственно, доминирование в отечественной экономике корпоративных структур, интегрированных в периферийную зону глобальной экономики, запускает следующие процессы:

- вытеснение из экономики корпораций, занимающихся разработкой технологий и выпуском продуктов машиностроения; 
- фиксация малоперспективной модели квазиразвития [13].

Структура участия 600 крупнейших корпораций России в формировании ВВП представлена на рисунке.

Данные на рисунке иллюстрируют довольно низкую долю не только высокотехнологичных корпораций в ВВП, но и продуктов с долей добавленной стоимости, потому что попытка импортозамещения обернулась ростом производств, ориентированных на примитивные технологии и применение ручного труда.

В российской экономике формируется разрыв в инвестиционной привлекательности поляризованных субъектов корпоративного капитала. Сетевые структуры новой экономики притягивают к себе дополнительный капитал, а корпоративные структуры сырьевой экономики отталкивают его от себя. Здесь ослабляются и зачастую полностью затухают проникающие из внешней среды импульсы постиндустриальных преобразований. Вместе с тем корпоративный капитал ряда секторов такой экономики вынужден выходить на мировые рынки, конкурировать, формировать необходимые преимущества. Возникают зоны нового роста, генерирующие импульсы преобразований и адресующие их существующей системе социально-экономических отношений. Корпоративный капитал начинает маневрировать, изменяется сам и обусловливает системные изменения; однако данный процесс может протекать вяло, охватывая длительный период, или вообще угасать, если система социально-экономических отношений отчуждена от преобразований и остается качественно неизменной.

За последние годы в конформировании развития корпоративного капитала возник новый фактор - противоречия развития постиндустриальных преобразований и изменения в технологиях производства, их пространственном распределении привели к осмыслению необходимости реиндустриализации национальной экономики, позволяющей создать качественно новую индустриальную базу, способную обеспечить технологические потребности постиндустриальных преобразований [6]. Старая промышленность, отвечавшая потребностям централизованной экономики, была обрушена в ходе рыночных преобразований, но торгово-развлекательные центры и жилищные комплексы, возведенные на оставшихся после нее инфраструктурных площадках, не могут стать связующим звеном между индустриальным и постиндустриальным строем общественной жизни. Для обеспечения стратегической конкурентоспособности корпоративного капитала реиндустриализация стала жизненно необходимым процессом [7].
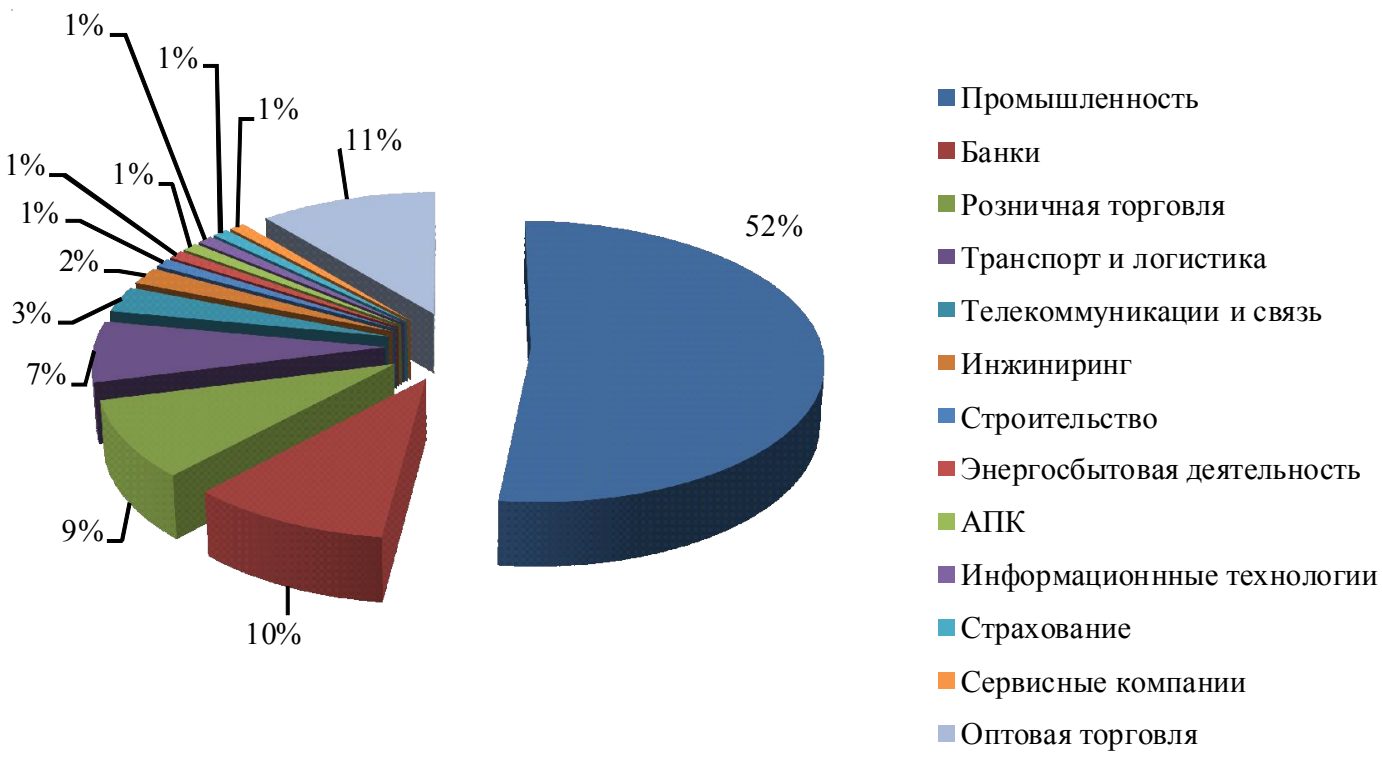

Рисунок. Доля выручки 600 крупнейших корпораций к ВВП за 2015 г. в России по отраслям, \% Примечание. Составлено авторами по: [3]. 
Политика реиндустриализации и инструменты ее реализации позволят преодолеть негативную поляризацию корпоративного капитала. Система экономики должна быть готова к их осуществлению, для чего востребовано воссоздание технологических промышленных комплексов на новой основе [14; 15].

Источником дополнительных ресурсов развития в условиях низкой инвестиционной привлекательности является использование возможностей воспроизводства фиктивного капитала и восстановление общественного доверия к национальному финансовому рынку, подорванного в последние годы реформ. Если такие возможности будут реализованы, то это приведет к расширению сбережений и эффективной трансформации их в инвестиции. Соответственно, при проведении реиндустриализации необходим строгий общественно-государственный контроль над инвестиционным процессом.

В заключение подчеркнем, что воссоздание промышленного производства на новой технологической базе российской экономики приведет к эффективному взаимодействию и соединению сетевых и корпоративных форм экономических отношений, трансформируя вертикальных механизмов в сетевые механизмы, отличающиеся большей адаптивностью.

\section{СПИСОК ЛИТЕРАТУРЫ}

1. Белл, Д. Социальные рамки информационного общества / Д. Белл // Новая технократическая волна на Западе. - М. : Прогресс, 1986.

2. Бодрунов, С. Д. Ресурсные преимущества России как основа высокотехнологичного экономического роста / С. Д. Бодрунов // Экономическое возрождение России. - 2014. - № 4 (42). - С. 24-31.

3. Брижак, О. В. Вклад отечественных корпораций в развитие национальной экономики : монография / О. В. Брижак. - Москва : ТЕИС, 2016. $152 \mathrm{c}$.

4. Бузгалин, А. В. Глобальный капитал. В 2 т. Т. 1 / А. В. Бузгалин, А. И. Колганов. - М. : ЛЕНАНД, 2015. $-912 \mathrm{c}$.

5. Глазьев, С. Ю. Мировой экономический кризис как процесс смены технологических укладов / С. Ю. Глазьев // Вопросы экономики. -2009. - № 3.

6. Губанов, С. С. Державный прорыв. Неоиндустриализация России и вертикальная интеграция / С. С. Губанов. - М. : Книжный мир, 2012.
7. Ермоленко, А. А. Концепт конформизма: новые возможности в исследовании трансформации экономических отношений / А. А. Ермоленко, O. В. Брижак // TERRA ECONOMICUS. - 2017. № 3. - C. 92-105.

8. Индикаторы инновационной деятельности: 2014 : стат. сб. - М., 2014. - 472 c.

9. Кастельс, М. Информационная эпоха: экономика, общество и культура / М. Кастельс ; пер. с англ. под науч. ред. О. И. Шкаратана. - М. : ГУ ВШЭ, 2000. $-608 \mathrm{c}$.

10. Клочко, Е. Н. Сектор виртуальных услуг в современной экономике сервиса: функциональное содержание, принципы управления, социальная инфраструктура /Е. Н. Клочко. - Краснодар : ЮИМ, 2012.

11. Ковалева, Г. Г. Информационная индустрия в России / Г. Г. Ковалева, М. А. Кевеш. - Электрон. текстовые дан. - Режим доступа: issek.hse.ru. Загл. с экрана.

12. Маркс, К. Капитал / К. Маркс. - М. : ИПЛ, 1978. - Т. 3, ч. 2.

13. Маркс, К. Экономическо-философские рукописи / К. Маркс, Ф. Энгельс // Сочинения / К. Маркс, Ф. Энгельс. - М. : Политиздат, 1974. - Т. 42.

14. Нижегородцев, Р. Экономика инфляционного разрыва / Р. Нижегородцев // Альтернативы. 2012. - № 3. - C. 141-151.

15. Нуреев, Р. М. Периферия мирового хозяйства / Р. М. Нуреев // Terra economicus. - 2014. - № 1.

16. Рязанов, В. Т. (Не)реальный капитализм. Политэкономия кризиса и его последствия для мирового хозяйства и России / В. Т. Рязанов. - М. : Экономика, 2016. - 695 с.

17. Флорида, Р. Креативный класс: люди, которые меняют будущее / Р. Флорида. - М. : КлассикаXXI, 2007. $-355 \mathrm{c}$.

\section{REFERENCES}

1. Bell D. Sotsialnye ramki informatsionnogo obshchestva [The Social Framework of the Information Society]. Novaya tekhnokraticheskaya volna na Zapade [New Technocratic Wave in the West]. Moscow, Progress Publ., 1986.

2. Bodrunov S.D. Resursnyye preimushchestva Rossii kak osnova vysokotekhnologichnogo ekonomicheskogo rosta [Russia's Resource Benefits as the Basis of High-Tech Economic Growth]. Ekonomicheskoe vozrozhdenie Rossii, 2014, no. 4 (42), pp. 24-31.

3. Brizhak O.V. Vklad otechestvennykh korporatsiy $v$ razvitiye natsionalnoy ekonomiki: monografiya [Contribution of Domestic Corporations to the Development of National Economy: Monograph]. Moscow, TEIS Publ., 2016. 152 p. 
4. Buzgalin A.V., Kolganov A.I. Globalny kapital. V2 t. T. 1 [The Global Capital. In 2 vols. Vol. 1]. Moscow, LENAND Publ., 2015. 912 p.

5. Glazyev S.Yu. Mirovoy ekonomicheskiy krizis kak protsess smeny tekhnologicheskikh ukladov [The World Economic Crisis as a Process of Changing the Technological Styles]. Voprosy ekonomiki, 2009, no. 3.

6. Gubanov S.S. Derzhavnyy proryv. Neoindustrializatsiya Rossii $i$ vertikalnaya integratsiya [Power Breakthrough. NeoIndustrialization of Russia and Vertical Integration]. Moscow, Knizhnyy mir Publ., 2012.

7. Ermolenko A.A., Brizhak O.V. Kontsept konformizma: novyye vozmozhnosti $\mathrm{v}$ issledovanii transformatsii ekonomicheskikh otnosheniy [Concept of Conformism: New Opportunities in the Study of Economic Relations' Transformation]. TERRA ECONOMICUS, 2017, no. 3, pp. 92-105.

8. Indikatory innovatsionnoy deyatelnosti: 2014 : stat. sb. [Indicators ofInnovation Activity: 2014. Statistical Compilation]. Moscow, GUVShE Publ., 2014. 472 p.

9. Kastels M. Informatsionnaya epokha: ekonomika. obshchestvo i kultura [Information Age: Economics, Society and Culture]. Moscow, GU VShE Publ., 2000. 608 p.

10. Klochko E.N. Sektor virtualnykh uslug v sovremennoy ekonomike servisa: funktsionalnoye soderzhaniye. printsipy upravleniya. sotsialnaya infrastruktura [The Sector of Virtual Services in the Modern Economy of Service: Functional Content, Management Principles, Social Infrastructure]. Krasnodar, YuIM Publ., 2012.

11. Kovaleva G.G., Kevesh M.A. Informatsionnaya industriya $v$ Rossii [Information Industry in Russia]. URL: issek.hse.ru.

12. Marx K. Kapital [Capital]. Moscow, IPL Publ., 1978, vol. 3, part 2.

13. Marx K., Engels F. Ekonomichesko-filosofskie rukopisi [Economical and Philosophical Manuscripts]. Moscow, Politizdat Publ., 1974.

14. Nizhegorodcev R. Ekonomika inflyatsionnogo razryva [Economics of the Inflationary Gap]. Alternativy, 2012, no. 3, pp. 141-151.

15. Nureev R.M. Periferiya mirovogo khozyaystva [Periphery of the World Economy]. Terra economicus, 2014, no. 1.

16. Ryazanov V.T. (Ne)realnyy kapitalizm. Politekonomiya krizisa i ego posledstviya dlya mirovogo khozyaystva i Rossii [(Not) Real Capitalism. The Political Economy of the Crisis and Its Consequences for the World Economy and Russia]. Moscow, Ekonomika Publ., 2016. 695 p.

17. Florida R. Kreativnyy klass: lyudi, kotorye menyayut budushchee [Creative Class: People Who Change the Future]. Moscow, Klassika-XXI Publ., 2007. $355 \mathrm{p}$.

\section{Information about the Authors}

Olga V. Brizhak, Candidate of Sciences (Economics), Associate Professor, Department of Economic Theory and Investments, Kuban State Technological University, Moskovskaya St., 2, 350072 Krasnodar, Russian Federation, brizhak71@mail.ru.

Marina E. Buyanova, Doctor of Sciences (Economics), Professor, Head of Department of Economic Theory, World and Regional Economy, Volgograd State University, Prosp. Universitetsky, 100, 400062 Volgograd, Russian Federation, buyanovam@rambler.ru.

\section{Информация об авторах}

Ольга Валентиновна Брижак, кандидат экономических наук, доцент кафедры экономической теории и инвестиций, Кубанский государственный технологический университет, ул. Московская, 2, 350072 г. Краснодар, Российская Федерация, brizhak71@mail.ru.

Марина Эдуардовна Буянова, доктор экономических наук, профессор, заведующая кафедрой экономической теории, мировой и региональной экономики, Волгоградский государственный университет, просп. Университетский, 100, 400062 г. Волгоград, Российская Федерация, buyanovam@rambler.ru. 